\title{
An improved biosensor for acetaldehyde determination using a bienzymatic strategy at poly(neutral red) modified carbon film electrodes
}

\author{
Mariana Emilia Ghica ${ }^{\mathrm{a}}$, Rasa Pauliukaite ${ }^{\mathrm{a}}$, Nicolas Marchand ${ }^{\mathrm{b}}$, \\ Eric Devic ${ }^{\mathrm{b}}$, Christopher M.A. Brett ${ }^{\mathrm{a}, *}$ \\ a Departamento de Química, Universidade de Coimbra, 3004-535 Coimbra, Portugal \\ ${ }^{\mathrm{b}}$ GTP Technology, Prologue Biotech, BP 28262, 31681 Laberge Cedex, France
}

Received 16 January 2007; received in revised form 15 March 2007; accepted 21 March 2007

Available online 25 March 2007

\begin{abstract}
Improved biosensors for acetaldehyde determination have been developed using a bienzymatic strategy, based on a mediator-modified carbon film electrode and co-immobilisation of NADH oxidase and aldehyde dehydrogenase. Modification of the carbon film electrode with poly(neutral red) mediator resulted in a sensitive, low-cost and reliable NADH detector. Immobilisation of the enzymes was performed using encapsulation in a sol-gel matrix or cross-linking with glutaraldehyde. The bienzymatic biosensors were characterized by studying the influence of $\mathrm{pH}$, applied potential and co-factors. The sol-gel and glutaraldehyde biosensors showed a linear response up to $60 \mu \mathrm{M}$ and $100 \mu \mathrm{M}$, respectively, with detection limits of $2.6 \mu \mathrm{M}$ and $3.3 \mu \mathrm{M}$ and sensitivities were $1.7 \mu \mathrm{A} \mathrm{mM}^{-1}$ and $5.6 \mu \mathrm{AmM} \mathrm{m}^{-1}$. The optimised biosensors showed good stability and good selectivity and have been tested for application for the determination of acetaldehyde in natural samples such as wine.
\end{abstract}

(C) 2007 Elsevier B.V. All rights reserved.

Keywords: Nicotinamide adenine dinucleotide oxidase; Aldehyde dehydrogenase; Carbon film electrode; Poly(neutral red); Enzyme cross-linking; Sol-gel

\section{Introduction}

Acetaldehyde has a widespread natural occurrence. It occurs in oak and tobacco leaves and is a natural component of apples, broccoli, coffee, grapefruit, grapes, lemons, mushrooms, onions, oranges, peaches, pears, pineapples, raspberries and strawberries; consumers may be exposed to acetaldehyde in cheese, heated milk, cooked beef, cooked chicken and rum [1]. Wherever fermentation processes play a role in the production of food and beverages, the concentration of acetaldehyde rises considerably. Acetaldehyde is commonly found in alcoholic beverages as a result of the enzymatic oxidation of ethanol; it is more toxic than ethanol and plays an important role in the manifestation of alcohol intoxication. The concentration of acetaldehyde is a very important parameter because of its capacity of reacting with sul-

\footnotetext{
* Corresponding author. Tel.: +351 835295; fax: +351835295 .

E-mail address: brett@ci.uc.pt (C.M.A. Brett).
}

phur dioxide to form a very stable combination, thus, preventing it from exercising its antioxidant and antiseptic function. Additionally, it is one of the earliest parameters to be noticeably affected when malfunction occurs during wine production. Due to its strong electrophilic properties acetaldehyde is believed to induce biological changes such as mutagenesis and carcinogenesis by reacting with DNA [2]. Therefore, a rapid and accurate assay for acetaldehyde determination is useful in food chemistry (wine, beer, yoghurts, etc.).

The determination of acetaldehyde in beverages can be performed in different ways: chemical methods based on distillation of acetaldehyde [3], colorimetric methods [4] gas chromatographic [5,6], liquid chromatographic [7,8] and enzymatic methods $[9,10]$. Despite their good analytical characteristics, these methods have a number of disadvantages such as a poor detection limit, e.g. $0.8 \mathrm{mM}$ [11], in the case of chemical methods, high cost and the necessity to decolorize and filter or degas samples before each assay in the case of enzymatic methods [12]. 
The determination of acetaldehyde in beverages using the enzymatic method uses the enzyme-catalysed reaction:

$$
\mathrm{CH}_{3} \mathrm{CHO}+\mathrm{NAD}^{+}+\mathrm{H}_{2} \mathrm{O} \stackrel{\mathrm{AldDH}}{\longrightarrow} \mathrm{CH}_{3} \mathrm{COOH}+\mathrm{NADH}+\mathrm{H}^{+}
$$

where AldDH is aldehyde dehydrogenase. The amount of $\mathrm{NADH}$ formed is equal to the amount of acetaldehyde consumed and can be determined by monitoring its absorbance at $340 \mathrm{~nm}$. The determination of NADH can be electrochemically monitored, but a high potential must be applied [13] and other compounds can be oxidized at such potentials.

Biosensor configurations for the detection of toxic inhibitors $[14,15]$ or for the determination of acetaldehyde have been previously reported by using aldehyde dehydrogenase in combination with diaphorase and addition of hexacyanoferrate to the working medium [13] or aldehyde dehydrogenase in combination with NADH oxidase [16]. Alternatively, electron transfer mediators, which react with NADH and reduce the potential necessary for its oxidation, have been used [11,12].

The electropolymerisation of phenothiazine dyes to form stable sensors for NADH is well documented in the literature $[17,18]$. Of these dyes, neutral red has been used for the preparation of electropolymerised films and electrochemical sensors based on the electroreduction of $\mathrm{NAD}^{+}$at poly(neutral red) (PNR) [19].

Carbon film electrodes represent attractive support electrodes because they are cheap, easy to fabricate, small and adaptable as disposable or short-term use sensors [20-22]. They have properties similar to glassy carbon and after electrochemical pre-treatment have large potential window and low background current [23]. Recently, electrochemical enzyme biosensors on carbon film electrode supports have been developed using poly(neutral red) redox mediator for measurements in complex matrices [24,25].

The aim of the present work is the development and characterization of improved electrochemical biosensors for acetaldehyde, by using a bienzymatic strategy at carbon film-based electrodes, and application to the control of wine quality. The biosensor is based on the immobilization of FMN-dependent $\mathrm{NADH}$ oxidase and $\mathrm{NAD}^{+}$-dependent aldehyde dehydrogenase on carbon film electrodes and using PNR as redox mediator. The enzymes were immobilised using two different strategies: cross-linking with glutaraldehyde (GA) and entrapment in sol-gel based on 3-glycidoxypropyltrimethoxysilane (GOPMOS), and methyltrimethoxysilane (MTMOS). The amperometric response for both immobilization strategies was evaluated when using monoenzymatic and bienzymatic biosensors and furthermore the biosensors were optimised for use in the determination of acetaldehyde in wine samples.

\section{Experimental}

\subsection{Materials}

Aldehyde dehydrogenase (AldDH, EC 1.2.1.5, from baker's yeast, $1.1 \mathrm{U} / \mathrm{mg}$ ) was from Fluka (Switzerland). Recombi- nant NADH oxidase (NADHOx, from Thermus thermophilus, $33.5 \mathrm{U} / \mathrm{mL}$ in $50 \mathrm{mM}$ sodium phosphate buffer $\mathrm{pH} 7.4+250 \mathrm{mM}$ $\mathrm{NaCl}$ ) was produced in $E$. coli and purified by GTP Technology (France).

Flavin mononucleotide (FMN) was from Fluka (Switzerland), $\beta$-nicotinamide adenine dinucleotide ( $\beta$-NAD), $\beta$ nicotinamide adenine dinucleotide reduced form $(\beta-\mathrm{NADH})$, bovine serum albumin (BSA), and glutaraldehyde (GA, 25\% volume fraction in water) were obtained from Sigma (Germany). Nafion (5\% volume fraction in ethanol) and Neutral Red (NR) monomer- $N^{8}, N^{8}, 3$-trimethylphenazine-2,8,-diamine - were purchased from Aldrich (Germany), and $\mathrm{KNO}_{3}$ was from Riedel-de-Haën (Germany).

Two trioxysilanes were used for enzyme encapsulation: 3-glycidoxypropyltrimethoxysilane (GOPMOS), and methyltrimethoxysilane (MTMOS) obtained from Aldrich (Germany).

Phosphate buffer, $0.1 \mathrm{M}$, or phosphate buffer saline (PBS), of different $\mathrm{pH}$ values between 6.0 and 8.0, were used as electrolytes, prepared from sodium dihydrogenphosphate and disodium hydrogenphosphate (Riedel-de-Haën, Germany), $0.05 \mathrm{M} \mathrm{NaCl}$ was added to make the PBS. Millipore Milli-Q nanopure water (resistivity $>18 \mathrm{M} \Omega \mathrm{cm}$ ) was used for preparation of all solutions. Experiments were performed at room temperature, $25 \pm 1{ }^{\circ} \mathrm{C}$.

\subsection{Instrumentation}

A three-electrode electrochemical cell was used for electrochemical measurements. It contained the enzyme/PNRmodified carbon film working electrode, a platinum foil as counter electrode and a saturated calomel electrode (SCE) as reference. Electrochemical measurements were performed using a computer-controlled $\mu$-Autolab Type II potentiostat/galvanostat running with GPES 4.9 software (EcoChemie, Utrecht, The Netherlands) or a Bioanalytical Systems (BAS, West Lafayette, IN) CV-50W electrochemical analyzer, controlled by BAS CV 2.1 software.

The $\mathrm{pH}$ measurements were carried out with a CRISON 2001 micro $\mathrm{pH}$-meter.

\subsection{Procedures}

\subsubsection{Electrode preparation}

Electrodes were made from carbon film resistors (resistance $\sim 2 \Omega$ ) $[23,26]$. Electrode preparation protocol is described elsewhere $[23,26]$. The exposed electrode geometric area was $\sim 0.20 \mathrm{~cm}^{2}$. Before use the electrodes were electrochemically pre-treated by cycling the applied potential between 0.0 and $+1.0 \mathrm{~V}$ versus $\mathrm{SCE}$ in $0.1 \mathrm{M} \mathrm{KNO}_{3}$ solution for not less than 10 cycles, until stable cyclic voltammograms were obtained.

Poly(neutral red) films were obtained by electrochemical polymerisation as described before [24]. Neutral Red was polymerised electrochemically by cycling the applied potential between -1.0 and $+1.0 \mathrm{~V}$ versus SCE for 15 times at a scan rate of $50 \mathrm{mV} \mathrm{s}^{-1}$ in a solution containing $1 \mathrm{mM} \mathrm{NR}$ monomer, $0.05 \mathrm{M}$ phosphate buffer $\mathrm{pH} 5.5$ and $0.1 \mathrm{M} \mathrm{KNO}_{3}$.

Sol-gel solution was prepared by mixing GOPMOS, MTMOS and water in amounts: 130:70:600 $\mu \mathrm{L}$, and adding 
$2 \mu \mathrm{L}$ of $6 \mathrm{M} \mathrm{HCl}$. The mixture was intensively mixed for $2 \mathrm{~min}$ and then sonicated for $15 \mathrm{~min}$ in order to accelerate hydrolysis of the precursors. The alcohol formed during hydrolysis was removed by heating the solution at $\sim 70^{\circ} \mathrm{C}$ for up to $30 \mathrm{~min}$ until the solution lost $40 \%$ of its volume. Then the solution was cooled down and neutralized to $\mathrm{pH} 7.0$ with $0.1 \mathrm{M} \mathrm{NaOH}$ solution. From this mixture $5 \mu \mathrm{L}$ was mixed with $2 \mu \mathrm{L}$ of NADHOx solution and, for the acetaldehyde biosensor, $2 \mu \mathrm{L}$ of AldDH ( $2 \%$ in $0.1 \mathrm{M}$ PBS $\mathrm{pH} 7.0$ ) was also added and mixed carefully. The mixture was left for an hour for gelation to start. When gelation began, PNR-coated carbon film electrodes were immersed in the sol-gel-enzyme solution for $5 \mathrm{~min}$, then removed and left for sol-gel formation at $4{ }^{\circ} \mathrm{C}$ for 3 days. All biosensors were stored dry at $4{ }^{\circ} \mathrm{C}$ until the first use.

For cross-linking immobilisation, mixtures of the enzymes with glutaraldehyde and BSA were prepared by direct mixing of the components as follows: (1) For the acetaldehyde bienzymatic biosensor: $2 \mu \mathrm{L}$ AldDH ( $2 \%$ in 0.1 M PBS pH 7.0), $2 \mu \mathrm{L}$ NADHOx, $2 \mu \mathrm{L}$ GA $(2.5 \%)$ and $2 \mu \mathrm{L}$ BSA (5\% in $0.1 \mathrm{M} \mathrm{PBS}$ $\mathrm{pH}$ 7.0); (2) For the NADH monoenzymatic biosensor: $4 \mu \mathrm{L}$ NADHOx, $2 \mu \mathrm{L}$ GA $(2.5 \%)$ and $2 \mu \mathrm{L}$ BSA (5\% in $0.1 \mathrm{M}$ PBS pH 7.0); (3) For the acetaldehyde monoenzymatic biosensor, $2 \mu \mathrm{L}$ AldDH ( $2 \%$ in $0.1 \mathrm{M}$ PBS pH 7.0), $2 \mu \mathrm{L} \mathrm{GA}(2.5 \%)$ and $2 \mu \mathrm{L}$ BSA (5\% in $0.1 \mathrm{M}$ PBS pH 7.0). In all cases $5 \mu \mathrm{L}$ of the mixture obtained was placed onto a PNR-modified carbon film electrode and allowed to dry at room temperature. Biosensors were left 2 days to stabilise before being used. When not in use the biosensors were kept in buffer solution at $4{ }^{\circ} \mathrm{C}$.

\subsubsection{Analysis of wine samples}

For analysis of acetaldehyde in wine, the standard addition method was used. This consisted of adding $100 \mu \mathrm{L}$ aliquot of wine to $10 \mathrm{~mL}$ of phosphate buffer, corresponding to 100 -fold dilution, the current being continuously monitored. When the response signal became stable, the solution was spiked with $10 \mu \mathrm{L}$ of $20 \mathrm{mM}$ acetaldehyde in phosphate buffer and the current recorded after stabilisation. The spiking was repeated three times after which the standard addition plot was constructed.

Independent analysis of acetaldehyde concentrations was performed using the spectrophotometric enzyme assay kit [27] (Cat 10668613 035, Boehringer, Mannheim, Germany). This consists in conversion of acetaldehyde to acetic acid by aldehyde dehydrogenase in the presence of $\mathrm{NAD}^{+}$. The amount of NADH formed, which is equal to the amount of acetaldehyde, is determined by means of light absorbance at $340 \mathrm{~nm}$. Measurements were done using a Speccord S100 spectrophotometer (Carl Zeiss, Jena, Germany).

\section{Results and discussion}

\subsection{Sol-gel encapsulation biosensors}

\subsubsection{Sol-gel NADHOx biosensor}

NADHOx was first used to prepare a monoenzymatic PNRmediated biosensor for NADH monitoring according to:

$\mathrm{NADH}+\mathrm{H}^{+}+\mathrm{O}_{2} \stackrel{\mathrm{NADOx}}{\longrightarrow} \mathrm{NAD}^{+}+\mathrm{H}_{2} \mathrm{O}_{2}$
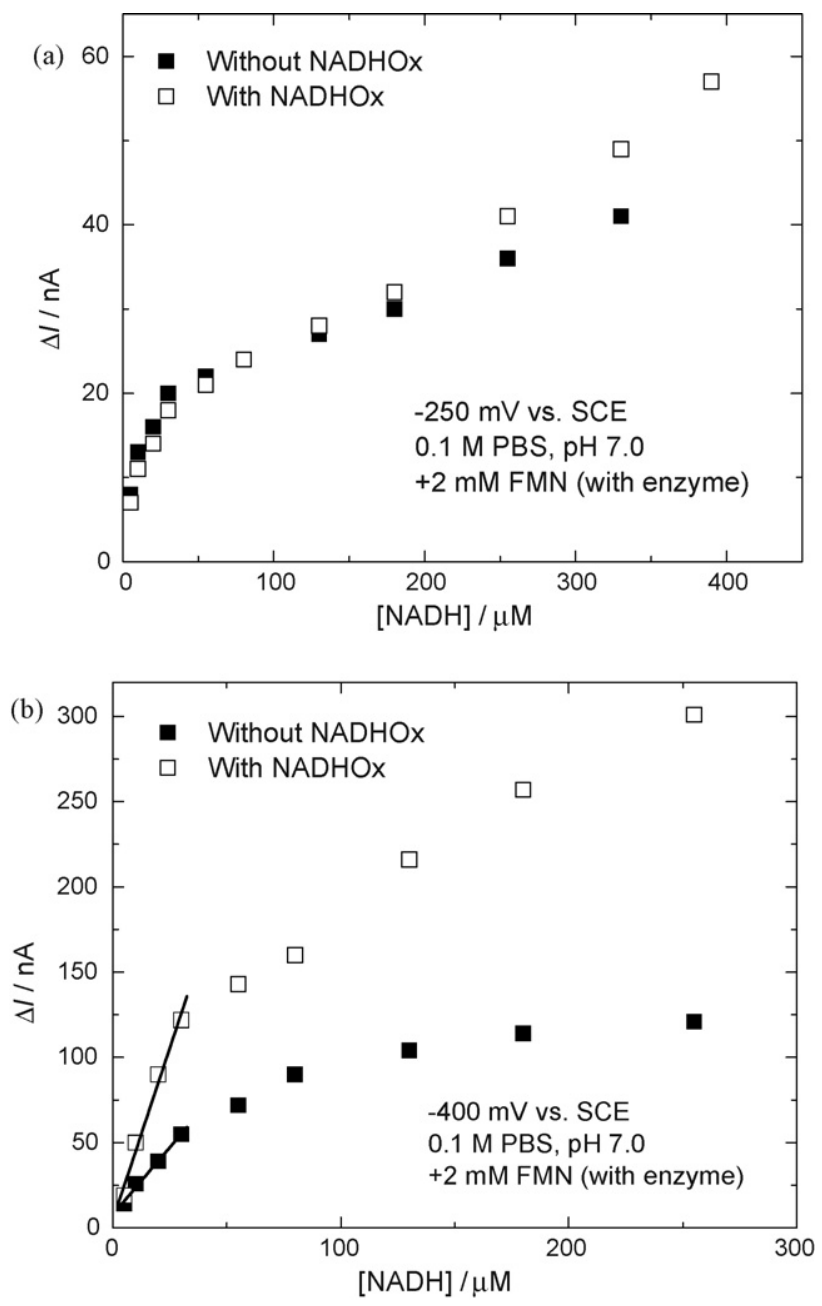

Fig. 1. Calibration curves for NADH obtained from chronoamperograms at PNR/sol-gel-NADHOx modified electrode in $0.1 \mathrm{M} \mathrm{PBS,} \mathrm{pH} 7.0$ with $2 \mathrm{mM}$ FMN at (a) $-0.25 \mathrm{~V}$ and (b) $-0.40 \mathrm{~V}$ vs. SCE.

The $\mathrm{H}_{2} \mathrm{O}_{2}$ formed during the enzymatic reaction can be determined at the mediator [28]:

$\mathrm{PNRH}_{2}+\mathrm{H}_{2} \mathrm{O}_{2} \rightarrow \mathrm{PNR}+2 \mathrm{H}_{2} \mathrm{O}$

It is also known that PNR increases the electrochemical rate of reduction of $\mathrm{NAD}^{+}$at $\sim-0.6 \mathrm{~V}$ at $\mathrm{pH} 6.0[19,29,30]$ :

$\mathrm{NAD}^{+}+\mathrm{PNRH}_{2} \rightarrow \mathrm{NADH}+\mathrm{PNR}+\mathrm{H}^{+}$

so that the biosensor cannot operate efficiently at this potential.

NADHOx is a FMN-dependent enzyme and this particular enzyme was produced without a co-factor, so it should be added. Experiments performed showed that the best response was obtained when FMN was added to the buffer solution rather than immobilised together with enzyme. The optimum FMN concentration was found to be $2 \mathrm{mM}$.

Fig. 1 shows the influence of NADHOx on NADH oxidation at the biosensor at $-0.25 \mathrm{~V}$ (Fig. 1a) and at $-0.40 \mathrm{~V}$ versus SCE (Fig. 1b). No difference was obtained determining NADH using the biosensor or just PNR by itself at $-0.25 \mathrm{~V}$ in $\mathrm{pH} 7$ buffer (Fig. 1a). However, at $-0.4 \mathrm{~V}$ the presence of NADHOx increases the sensitivity to NADH by a factor of two compared 

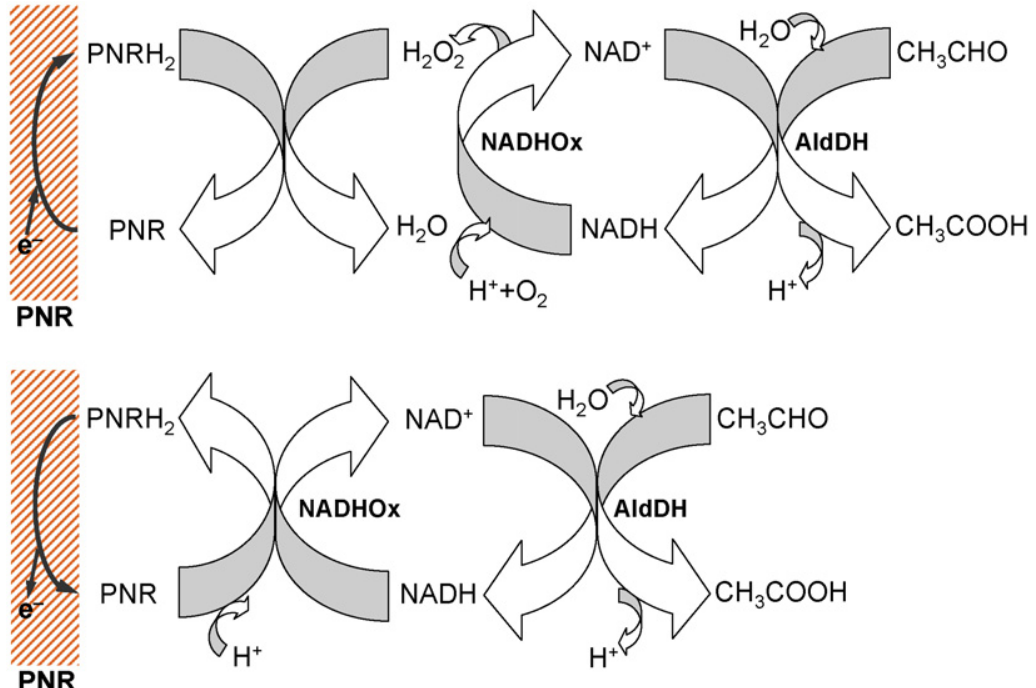

Fig. 2. Schematic mechanisms of the bienzymatic acetaldehyde biosensor: (a) via $\mathrm{H}_{2} \mathrm{O}_{2}$ determination, and (b) regeneration of $\mathrm{NAD}^{+}$at PNR.

to the response at PNR without any enzyme. This shows that the biosensor with PNR and NADHOx can be used for NADH monitoring in a more sensitive way. The response with enzyme was found to be similar to that with glucose oxidase [28], i.e. due to competition between two reactions, Eqs. (4) and (5), two linear ranges were obtained (Fig. 1, empty symbols). The best potential for the amperometric NADH biosensor mediated with PNR, should not be more negative than $-0.6 \mathrm{~V}$ to avoid any influence from the product of $\mathrm{NAD}^{+}$reduction and not more positive than $-0.25 \mathrm{~V}$ versus SCE to avoid an oxidation current from the mediator-NADH electrochemical reaction.

\subsubsection{Sol-gel acetaldehyde biosensor}

A bienzymatic sensor was prepared with both NADHOx and AlDH for acetaldehyde determination, where the $\mathrm{NAD}^{+}$necessary for acetaldehyde oxidation to acetic acid (see Eq. (1)) is regenerated according to Eq. (2). NADHOx oxidises NADH back to $\mathrm{NAD}^{+}$, as shown in the general mechanism presented in Fig. 2, in this way supplying the cofactor necessary for further AldDH activity.

In order to obtain the best potential for amperometric measurements, acetaldehyde was measured at the bienzymatic biosensor at different potentials. At first the background current in buffer solution was measured at the biosensors and then $1 \mathrm{mM}$ acetaldehyde was injected into the buffer solution and the resulting response measured at the same potentials. Fig. 3a shows the current response to $1 \mathrm{mM}$ acetaldehyde at each potential. At potentials more negative than $-0.40 \mathrm{~V}$ versus SCE a reduction response was obtained either due to $\mathrm{NAD}^{+}$or to acetaldehyde (which is reduced by PNR to ethanol) and so could not be used. The best potential with the highest oxidation current was $-0.40 \mathrm{~V}$, and all further measurements were carried out at this potential.

The next step was optimisation of $\mathrm{pH}$. An electrolyte of $0.1 \mathrm{M}$ phosphate buffer with addition of $2 \mathrm{mM}$ FMN was used from $\mathrm{pH}$ 5.5 to 8.0 , in intervals of $0.5 \mathrm{pH}$ units. The results are presented in Fig. $3 \mathrm{~b}$ and the best $\mathrm{pH}$ was 7.0 or 7.5 depending on acetaldehyde concentration. The optimum $\mathrm{pH}$ for NADHOx is 7.5-8.0 [31]; a similar value for AldDH [32] was reported but there AldDH was produced by different organism - bovine corneal - and in this work enzyme from baker's yeast. Since there was not a signifi-
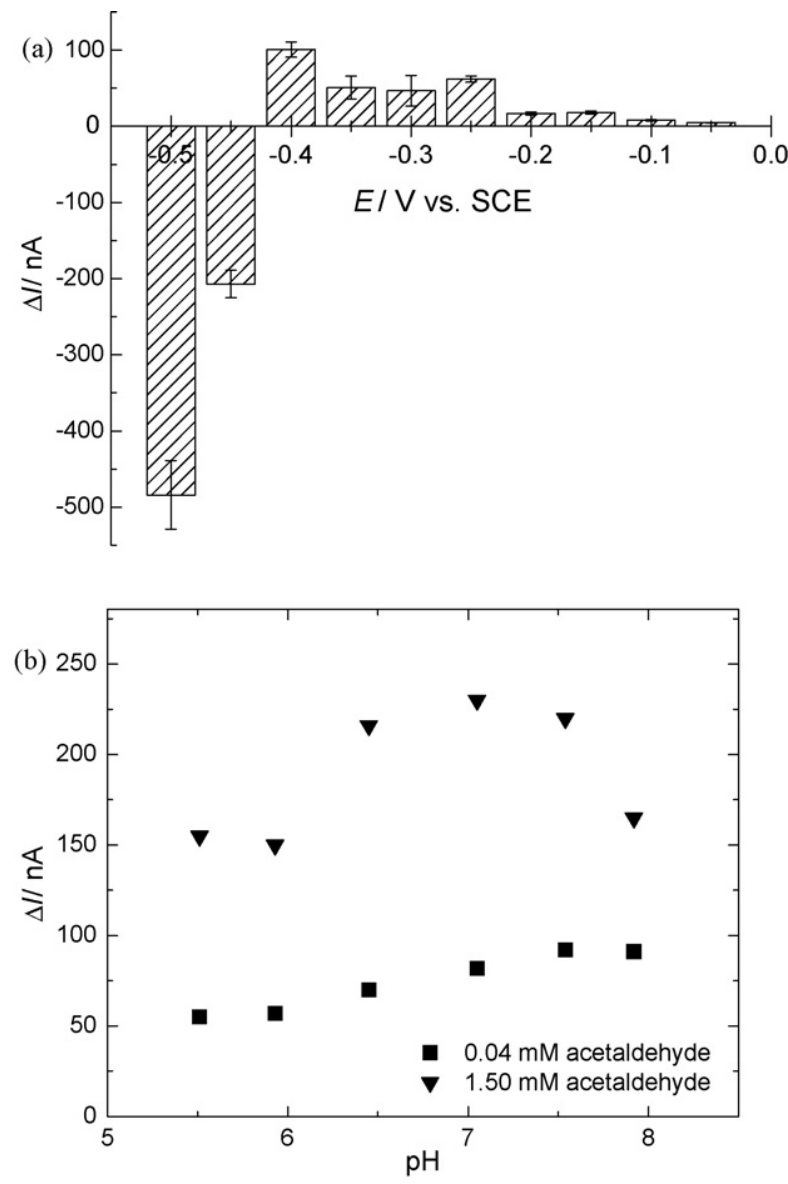

Fig. 3. (a) Amperometric response to $1 \mathrm{mM}$ acetaldehyde at different potentials in 0.1 M PBS pH 7.0. (b) Dependence of the response to acetaldehyde at bienzymatic sol-gel AldDH-NADHOx biosensor on solution $\mathrm{pH}$. Applied potential $-0.40 \mathrm{~V}$ vs. SCE. 
cant difference response at $\mathrm{pH} 7.0$ and 7.5, and also the fact that PNR is more active in neutral or weakly acid media, subsequent measurements were performed at pH 7.0 in 0.1 M PBS. Calibration of the sol-gel based bienzymatic biosensor was performed under optimised conditions at $-0.4 \mathrm{~V}$ versus SCE in $0.1 \mathrm{M}$ PBS, $\mathrm{pH} 7.0$, in the presence of $2 \mathrm{mM} \mathrm{FMN}$. The calibration data found were: linear range $10-60 \mu \mathrm{M}$; sensitivity $1.7 \mu \mathrm{A} \mathrm{mM}^{-1}$; limit of detection $(3 \sigma) 2.6 \mu \mathrm{M}$; correlation coefficient $\left(R^{2}\right) 0.990$; and the apparent Michaelis-Menten constant $\left(K_{\mathrm{M}}\right)$ obtained from Lineweaver-Burk linearisation was $1.4 \mathrm{mM}$.

PNR/sol-gel-AldDH-NADHOx electrodes were stable for at least 20 days. Stability was recorded at $-0.4 \mathrm{~V}$, in $0.1 \mathrm{M}$ PBS, $\mathrm{pH} 7.0$ by measuring the response to $0.04 \mathrm{mM}$ acetaldehyde. The relative response decreased slowly every day and after 20 days the signal dropped by $20 \%$.

\subsection{Glutaraldehyde cross-linking biosensors}

\subsubsection{Glutaraldehyde NADHOx biosensor}

In the same way as was done with sol-gel encapsulation, first a monoenzymatic biosensor using NADH oxidase was prepared using glutaraldehyde cross-linking as described in the experimental section and was tested for response to NADH in amperometric mode. As stated before, NADH can be oxidized directly at PNR-modified electrodes or by using NADHOx enzyme. The biosensor system here combines both mediator and enzyme, with the objective that NADH will be oxidized at a lower potential. In order to see if this occurs, NADH was determined at $-0.5 \mathrm{~V}$ versus SCE both at PNR-modified electrodes and at PNR/NADHOx-modified electrodes. The result was an increase in sensitivity at the latter by a factor of 2.4 leading to the conclusion that the biosensor in this configuration is more suitable.

An important factor to determine is whether FMN should be immobilised together with the enzyme or should be added to the buffer solution. It was observed that the biosensor's response was better when FMN was added to the buffer solution as in the case of the sol-gel-based biosensor. The influence of the concentration of FMN in the buffer was studied from 0 to $3 \mathrm{mM}$. The response significantly increases up to $2 \mathrm{mM} \mathrm{FMN}$ and for $3 \mathrm{mM}$ just a small increase in the response was observed. Therefore a concentration of $2 \mathrm{mM}$ FMN was chosen.

The NADH biosensor was also optimized with respect to $\mathrm{pH}$ at $-0.3 \mathrm{~V}$ and $-0.5 \mathrm{~V}$ versus SCE by injecting $30 \mu \mathrm{M}$ NADH in $0.1 \mathrm{M}$ sodium phosphate buffer in the $\mathrm{pH}$ range from 6.0 to 8.0. The results (Fig. 4) show that at both applied potentials, the higher response was at $\mathrm{pH} 6.5$.

\subsubsection{Glutaraldehyde acetaldehyde biosensor}

The proposed mechanism for the bienzymatic biosensor is described in Fig. 2. Two different biosensors were prepared: one with just the enzyme aldehyde dehydrogenase and the other with aldehyde dehydrogenase and NADH oxidase, and both were tested for acetaldehyde determination under the same conditions. The response is presented in Fig. 5 and it can be seen that when using the two enzymes together the response to acetaldehyde was better. With the bienzymatic system the sensitivity for acetaldehyde determination was increased by a factor of two.

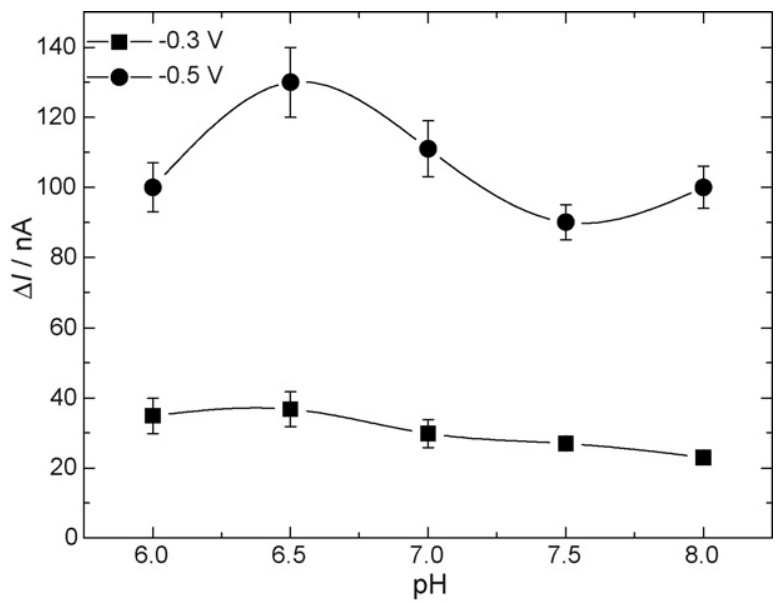

Fig. 4. The response for $30 \mu \mathrm{M}$ NADH of the PNR/NADHOx-GA biosensor at (ם) $-0.3 \mathrm{~V}$ and $(-)-0.5 \mathrm{~V}$ vs. SCE in $0.1 \mathrm{M} \mathrm{PBS}+2 \mathrm{mM}$ FMN at different $\mathrm{pH}$ values.

In order to optimise the biosensor performance, a series of parameters was studied, starting with the enzyme ratio. It was observed that there was not a very big difference between using a 1:1 or 1:4 ratio for AldDH:NADHOx (data not shown) — just an increase of $13 \%$ in sensitivity for a ratio of 1:4 and no improvement in detection limit. So for further experiments the enzymes were used in the ratio of $1: 1$.

As previously reported [11], acetaldehyde could be determined using two different approaches: $\mathrm{NAD}^{+}$immobilized together with the AldDH or added to the buffer solution. Both strategies were followed and the choice was to use the co-factor in the buffer solution since the response to the analyte was higher. The effect of the concentration of $\mathrm{NAD}^{+}$on biosensor response to the same acetaldehyde concentration was also examined. The response of the biosensor increases with the increase of $\mathrm{NAD}^{+}$concentration in the buffer. An increase of $62 \%$ was found when using $1 \mathrm{mM} \mathrm{NAD}^{+}$compared with no $\mathrm{NAD}^{+}$and a further increase of $12 \%$ from 1 to $2 \mathrm{mM} \mathrm{NAD}^{+}$. Therefore,

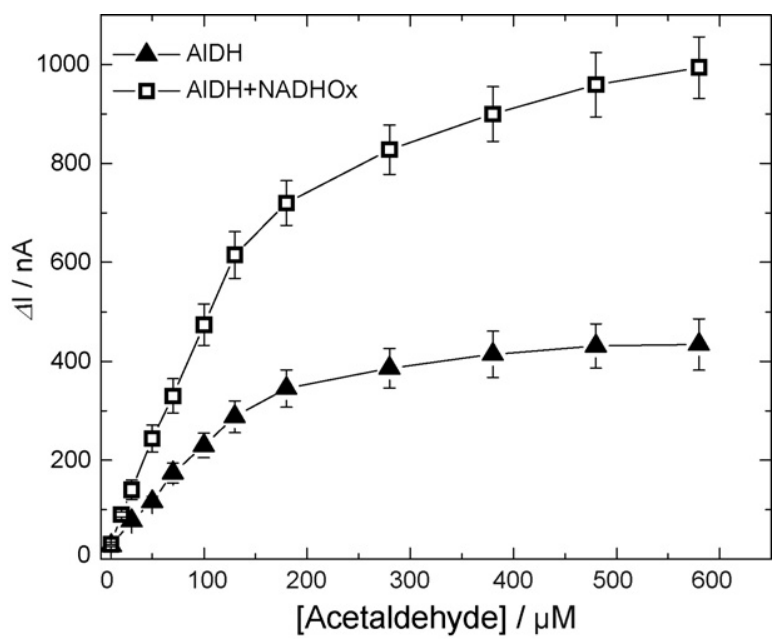

Fig. 5. Calibration curve for acetaldehyde at $-0.5 \mathrm{~V}$ vs. SCE using ( $\square$ ) AldDHNADHOx-GA or $(\boldsymbol{\Delta})$ AldDH-GA biosensor in $0.1 \mathrm{M}$ PBS $(\mathrm{pH} 7.5)+1 \mathrm{mM}$ $\mathrm{NAD}^{+}+2 \mathrm{mM}$ FMN. 

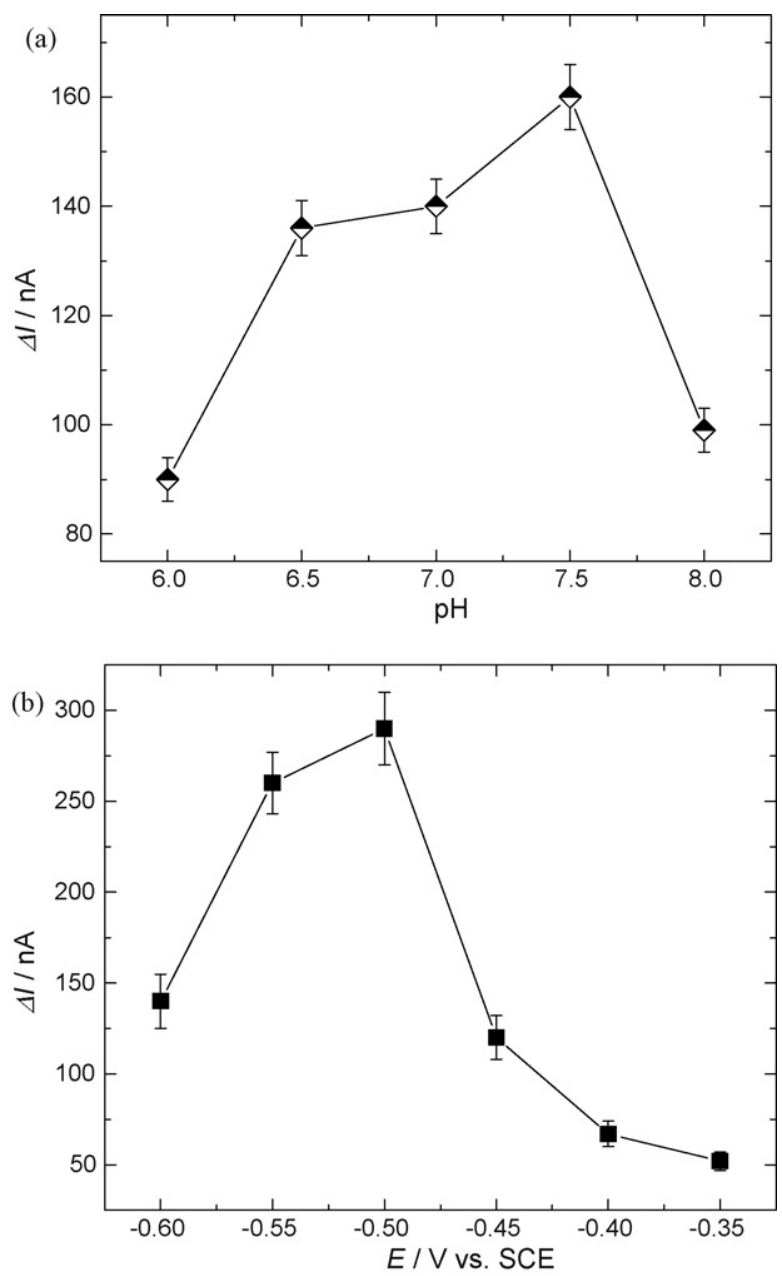

Fig. 6. (a) $\mathrm{pH}$ dependence at $-0.50 \mathrm{~V}$ vs. SCE for determination of $20 \mu \mathrm{M}$ acetaldehyde (b) potential dependence for determination of $60 \mu \mathrm{M}$ acetaldehyde at PNR/AIDH-NADHOx-GA biosensor in $0.1 \mathrm{M} \mathrm{PBS}+1 \mathrm{mM} \mathrm{NAD}^{+}+2 \mathrm{mM}$ FMN.

as a compromise between the biosensor performance and cost a concentration of $1 \mathrm{mM} \mathrm{NAD}^{+}$in the buffer solution was chosen.

The $\mathrm{pH}$ of the buffer solution is important when using immobilized enzymes in order to maintain them under their optimum functioning conditions. However, the most appropriate $\mathrm{pH}$ for best performance of the redox mediator also has to be taken into account. When tested in 0.1 M PBS at different $\mathrm{pH}$ values the response of the biosensor at the same acetaldehyde concentration led us to select pH 7.5 (Fig. 6a). This pH allows good performance for the enzyme and also for the mediator, which presents higher reactivity in neutral or weakly acid media than in alkaline media [33].

Optimisation of the working potential, involved measuring the response of the biosensor to $60 \mu \mathrm{M}$ acetaldehyde in phosphate buffer at different potentials in the range $-0.6 \mathrm{~V}$ to $-0.35 \mathrm{~V}$ versus SCE. The highest response was observed at a potential of $-0.5 \mathrm{~V}$ (Fig. 6b).

The biosensor was tested for response to acetaldehyde in amperometric mode with the optimised parameters, i.e. at $-0.5 \mathrm{~V}$ in $0.1 \mathrm{M}$ PBS $(\mathrm{pH} 7.5)+1 \mathrm{mM} \mathrm{NAD}+2 \mathrm{mM}$ FMN under stirring conditions, by adding known acetalde-
Table 1

Interference of some compounds on the response to acetaldehyde at PNR/AldDH-NADHOx-GA biosensor

\begin{tabular}{ll}
\hline Interferent & $\begin{array}{l}\text { Relative response }(\%) \text { acetaldehyde: } \\
\text { interferent ratio } 1: 1\end{array}$ \\
\hline Glucose & 100 \\
Fructose & 100 \\
Glycerol & 100 \\
Acetic acid & 100 \\
Ascorbic acid & 80 \\
Citric acid & 85 \\
Tartaric acid & 90
\end{tabular}

hyde concentrations. The calibration curve obtained was Michaelis-Menten like with the apparent kinetic constant $K_{\mathrm{M}}=0.23 \pm 0.03 \mathrm{mM}(n=3)$. The biosensor exhibited linear response to acetaldehyde up to $100 \mu \mathrm{M}$ with a sensitivity of $5.68 \mu \mathrm{A} \mathrm{mM}^{-1}$ and a limit of detection $(3 \sigma)$ of $3.3 \mu \mathrm{M}$.

Regarding operational stability, the bienzymatic biosensor was applied to the determination of $40 \mu \mathrm{M}$ acetaldehyde during $6 \mathrm{~h}$, which consisted in 11 measurements. After this period, the biosensor response dropped to $91 \%$ of the initial value. Storage stability was assessed by storing the enzyme electrode in buffer at $4{ }^{\circ} \mathrm{C}$ and performing a calibration curve once per week. After 3 weeks the biosensor still retained $83 \%$ of its initial sensitivity.

The selectivity of the biosensor was investigated under optimised conditions by testing the response to several compounds that are usually present in wines. The result of the study in a ratio of 1:1 acetaldehyde to interferent (Table 1) was a decrease in the acetaldehyde response with 10,15 and $20 \%$ by tartaric acid, citric acid and ascorbic acid, respectively and no interference from glucose, fructose, acetic acid or glycerol. The results obtained with the biosensor are good indications that it can be applied to the determination in natural samples such as wines. Therefore, the biosensor was applied for the determination of acetaldehyde in several dry (white and red) wines using the standard addition method. Taking into account the fact that the usual concentration of acetaldehyde in wine is between $0.7 \mathrm{mM}\left(30.8 \mathrm{mg} \mathrm{L}^{-1}\right)$ and $1.8 \mathrm{mM}\left(79.2 \mathrm{mg} \mathrm{L}^{-1}\right)$ [12] dilution of the samples was necessary. For comparison purpose the wines were also analysed using a spectrophotometric enzyme assay kit [27]. Acetaldehyde concentrations determined by the two methods are presented in Table 2 as the mean value of three determinations. The results

Table 2

Determination of acetaldehyde in wine samples with PNR/AldDH-NADHOxGA biosensor

\begin{tabular}{lcc}
\hline Type of wine & $\begin{array}{l}\text { Acetaldehyde }\left(\mathrm{mg} \mathrm{L}^{-1}\right) \\
\text { (amperometry) }\end{array}$ & $\begin{array}{l}\text { Acetaldehyde }\left(\mathrm{mg} \mathrm{L}^{-1}\right) \\
\text { (spectrophotometry) }\end{array}$ \\
\hline Red wine 1 & $106.1 \pm 5.4$ & $111.8 \pm 1.5$ \\
Red wine 2 & $187.5 \pm 2.2$ & $189.4 \pm 5.9$ \\
Red wine 3 & $125.9 \pm 4.4$ & $130.2 \pm 2.5$ \\
White wine 1 & $98.3 \pm 5.0$ & $99.9 \pm 2.5$ \\
White wine 2 & $70.7 \pm 2.5$ & $72.3 \pm 0.6$ \\
\hline
\end{tabular}


are in good agreement with less than $10 \%$ error, which means that the developed biosensor is a valuable tool for monitoring acetaldehyde.

\section{Conclusions}

Bienzymatic biosensors for acetaldehyde using two different immobilisation techniques (entrapment in sol-gel or crosslinking with glutaraldehyde) have been developed. In both cases the use of NADH oxidase in conjunction with aldehyde dehydrogenase led to the improvement of the acetaldehyde biosensor performance compared with aldehyde dehydrogenase by itself, due to regeneration of the $\mathrm{NAD}^{+}$co-factor of the dehydrogenase. After optimisation of the working conditions the biosensors showed linear response to acetaldehyde up to $60 \mu \mathrm{M}$ for the sol-gel and $100 \mu \mathrm{M}$ for the glutaraldehyde one, which is compatible with determination in natural samples, such as wines. Biosensors were stable for at least 20 days, which is good when used as disposable or short-time use biosensors. An interference study showed good selectivity and therefore the biosensor is suitable for measurement of acetaldehyde in natural samples. Good agreement between the acetaldehyde concentration values in red and white wines obtained with the biosensor and by a spectrophotometric method shows the biosensor to be a good and rapid alternative for acetaldehyde determination in natural samples.

\section{Acknowledgements}

Financial support from Fundação para Ciência e Tecnologia (FCT) Portugal, ICEMS, Portugal (Research Unit 103) and European Project HPRN-CT-2002-00186 "Novtech" is gratefully acknolwedged. M.E.G. thanks FCT for a Ph.D. grant (SFRH/BD/14014/2003) and R.P. for a postdoctoral fellowship (SFRH/BPD/14518/2003). Prof. H.-D. Liess is thanked for the gift of the electrical resistors.

\section{References}

[1] Report on Carcinogens, eleventh ed.; U.S. Department of Health and Human Services, Public Health Service, National Toxicology Program, 08/26/2005, pp.1-2.
[2] S.C. Guru, K.T. Shetty, Alcohol 7 (1990) 397.

[3] Official Methods of Analysis (1995) 16th ed., vol. 2, AOAC International, Arlington, VA, method 967.10

[4] J.L. Owades, J.M. Dono, J. Assoc. Off. Anal. Chem. 51 (1968) 148.

[5] G. Hagman, J. Roeraade, J. High Resolut. Chromatogr. 13 (2005) 99.

[6] R.A. Peinado, J.A. Moreno, D. Munoz, M. Medina, J. Moreno, J. Agric. Food. Chem. 52 (2004) 6389.

[7] R.F. Nascimento, J.C. Marques, B.S. Lima Neto, D. De Keukeleire, D.W. Franco, J. Chromatogr. A 782 (1997) 13.

[8] A.G.H. Lea, G.D. Ford, S. Fowler, Int. J. Food. Sci. Technol. 35 (2000) 105.

[9] J. Miyake, Agric. Food. Chem. 41 (1993) 1968.

[10] J.A. Delcour, J.M. Caers, P. Dondeyne, F. Delvaux, E. Robberechts, J. I. Brew. 88 (1982) 384.

[11] A. Avramescu, T. Noguer, M. Avramescu, J.-L. Marty, Anal. Chim. Acta 458 (2002) 203

[12] T. Noguer, A. Tencalie, C. Calas-Blanchard, A. Avramescu, J.-L. Marty, J. AOAC Int. 85 (2002) 1.

[13] T. Noguer, J.-L. Marty, Enzyme Microb. Technol. 17 (1995) 453.

[14] T. Noguer, A.-M. Balasoiu, A. Avramescu, J.-L. Marty, Anal. Lett. 34 (2001) 513.

[15] T. Noguer, A. Gradinaru, A. Ciucu, J.-L. Marty, Anal. Lett. 32 (1999) 1723.

[16] T. Noguer, J.-L. Marty, Anal. Lett. 30 (1997) 1069.

[17] A.A. Karyakin, A.K. Strakhova, E.E. Karyakina, S.D. Varfolomeyev, Bioelectrochem. Bioenerg. 32 (1993) 35.

[18] Y. Okamoto, T. Kaku, R. Shundo, Pure Appl. Chem. 68 (1996) 1417.

[19] A.A. Karyakin, O.A. Bobrova, E.E. Karyakina, J. Electroanal. Chem. 399 (1995) 179.

[20] O.M.S. Filipe, C.M.A. Brett, Talanta 61 (2003) 643.

[21] R. Pauliukaite, M.E. Ghica, C.M.A. Brett, Anal. Bioanal. Chem. 381 (2005) 972

[22] C. Gouveia-Caridade, C.M.A. Brett, J. Electroanal. Chem. 592 (2006) 113.

[23] C.M.A. Brett, L. Angnes, H.D. Liess, Electroanalysis 13 (2001) 765.

[24] M.E. Ghica, C.M.A. Brett, Electroanalysis 18 (2006) 748.

[25] M.E. Ghica, C.M.A. Brett, Anal. Lett. 39 (2006) 1527.

[26] O.M.S. Filipe, C.M.A. Brett, Electroanalysis 16 (2004) 994.

[27] H.-O. Beutler, in: H.U. Bergmeyer (Ed.), Methods of Enzymatic Analysis, vol.6, third ed., Verlag Chemie, Weinheim, Deerfield Beach, Florida, Basel, 1984, p. 606.

[28] R. Pauliukaite, M.E. Ghica, M. Barsan, C.M.A. Brett, J. Solid State Electrochem., in press, doi:10.1007/s10008-007-0281-9.

[29] A.A. Karyakin, Y.N. Ivanova, E.E. Karyakina, Electrochem. Commun. 5 (2003) 677

[30] S.M. Chen, K.C. Lin, J. Electroanal. Chem. 511 (2001) 101

[31] S. Serban, N. El Murr, Electrochim. Acta 51 (2006) 5143.

[32] M.J. Doughty, Cell. Biol. Intern. 28 (2004) 593.

[33] A.A. Karyakin, E.E. Karyakina, H.-L. Schmidt, Electroanalysis 11 (1999) 149. 